\title{
XXXV. The change of the order of absolute viscosity encountered on passing from fluid to solid
}

\section{Carl Barus}

To cite this article: Carl Barus (1890) XXXV. The change of the order of absolute viscosity encountered on passing from fluid to solid, Philosophical Magazine Series 5, 29:179, 337-355, DOI: $10.1080 / 14786449008619946$

To link to this article: http://dx.doi.org/10.1080/14786449008619946

曲 Published online: 08 May 2009.

Submit your article to this journal $[\pi$

ЏII Article views: 2

Q View related articles $\longleftarrow$ 
The sharp doublet $(m=2)$ is nearly coincident with the two lines which hitherto have been measured. The wave-lengths of these lines are, viz :-

After Lecoq de Boisbaudran. $\left.\begin{array}{l}4170 \\ 4031\end{array}\right\} \nu=826 \cdot 9$
After Deville and Mermet.

$\left.\begin{array}{l}4171 \\ 4033\end{array}\right\} \nu=820 \cdot 3$

The accordance is even better than could well be expected.

Finally, I will remark that the hypotheses of Mr. Lockyer on dissociation of the elements are quite incompatible with the results of my researches. The observations of Lockyer within the spectra of $\mathrm{Na}$ and $\mathrm{K}$ prove only that, with luminous atoms as with sounding bodies, the relative intensity of the partial tones may vary under different circumstances. For the lines in question belong, without doubt, to the same system of vibrations.

Lund, February 1890.

XXXV. The Change of the Order of Absolute Viscosity encountered on passing from Fluid to Solid. By CARL Barus.

1. Tho my knowledge nobody has thus far defined the difference between the solid state and the fluid states quantitatively. In the case of liquids and gases viscosity can be absolutely expressed with facility, and the data have therefore to be stated with considerable rigour. This is not true for solids, where the results are relative throughout.

The present paper submits two methods for the coordination of the viscous behaviour of solids and of liquids. In describing the differential method applied by Dr. Strouhal and myself + , we incidentally pointed out the way in which the relative viscosity of two solids may be stated in terms of the respective sectional areas, by which the motion at the junction of the two counter-twisted wires or rods is annulled. Suppose that one of the wires is a solid, whereas the other is a very viscous liquid. Then if the viscosity of the latter can just be measured by transpiration-methods $(\$ \S 4,5)$, it follows that the viscosity of the true solid with which it was countertwisted may also be absolutely expressed. This indicates the first method of the present paper $(\$ \S 8,9)$.

* Communicated by the Author.

† Barus and Strouhal, American Journal, xxxiii. p. 29 (1887). 


\section{Mr. C. Barus on the Change of the Order of Alsolute}

My second method for measuring the viscosity of solids absolutely is direct. It is capable of yielding results of any desirable accuracy, supposing the necessary facilities for an adjustment free from vibratory disturbances are given $(\S \S 12,13)$.

\section{Gases and Vapours.}

2. Results for the viscosity of gases and vapours are given by many observers *. The data present some curious aspects ; thus, for instance, the viscosity of vapours $\dagger$ is frequently smaller than the viscosity of gases. The order of viscosity $(\eta)$ is about $10^{-4} \mathrm{~g} / c s(c f . \S 18$. $)$. Results for the viscosity of substances in the neighbourhood of Andrew's's critical temperature are not available. Such an investigation would be highly desirable (§18).

\section{Liguids.}

3. The literature contains extensive researches and is systematized in Landolt and Boernstein's Physical Tables $\ddagger$. The data are easily expressed absolutely, by aid of Slotte's $\$$ values of the viscosity of water between $0^{\circ}$ and $100^{\circ}$. If water at $20^{\circ}$ be taken as a type liquid, $\eta=\cdot 01(g / c s)(c f . \S 18)$.

\section{Viscous Liquids.}

4. Data are wanting.

My experiments were made with marine glue $\|$. The method is simple. A fairly wide capillary tube, $a b c$, provided with a cylindrical open reservoir, $a$, at one end, was half filled with marine glue, the thread extending from the reservoir, $a$, as far down as the middle, $b$, of the tube. The other (open) end of the tube was inserted into the flask, $d d d d$, from which the air was then exhausted. Thus a pressure of about $\perp \mathrm{atm}$. is continually brought to bear on the reservoir $a$ of the tube, the other end, $c$, being in vacuo. A lateral arm, $e$, closed by fusion, facilitates the exhaustion. A small vacuum-

* Summarized in O. E. Meyer's Die kinetische Theorie der Gase, Breslau, 1877, pp. 138 et seq.

$\dagger$ The most complete set of data are those of Puluj, Phil. Mag. [5] vi. p. 157 (1878). Lothar Meyer, E. Wiedemann, and others have contributed to the subject.

I Physikalisch-chemische Tabellen : Berlin, J. Springer, 1883, p. 153.

$\S$ Slotte, Wied. Ann. xx.p. 267 (1888). References to other researches (O. E. Meyer, Poiseuille, Rosencranz) are there given.

II A valuable cement being (nominally) a specially prepared mixture of rubber and shellac. It has a pitchy consistency, and can be thickened by adding shellac. 
Viscosity encountered on passing from Fluid to Solid. 339

gauge, $g g$, held in place by a Fig. 1.-Apparatus for the Secular layer of paraffin, $h$, shows the observer to what degree the vacuum is maintained in the lapse of time. A number of tubes, $a b c$, may be inserted side by side, and it is always necessary to coat the stopper with cement.

5. The transpiration-equation due to Poiseuille, theoretically corrected by Hagenbach*, has the form

$$
\eta=\frac{\pi \mathrm{P}^{4}}{8 v l} t-\frac{m}{2^{10 / 3} \pi l} \frac{1}{t}, .
$$

where $\eta$ is the absolute viscosity of the liquid, $v$ the volume, and $m$ the mass transpiring through the capillary length $l$ and radius $r$, in the time $t$. In the present case of excessively slow transpiration the correction may be neglected. $P$ is the pressure-excess, in dynes per square centimetre. All magnitudes are to be expressed in C.G.S. units.

In the above form of apparatus (fig. 1 ) $l$ is not constant, and $v$ is measured in terms of the increase of length of the capillary thread $a b$ (fig. 1). Hence the differential equation corresponding to (1), since $d v=\pi r^{2} d l$, is

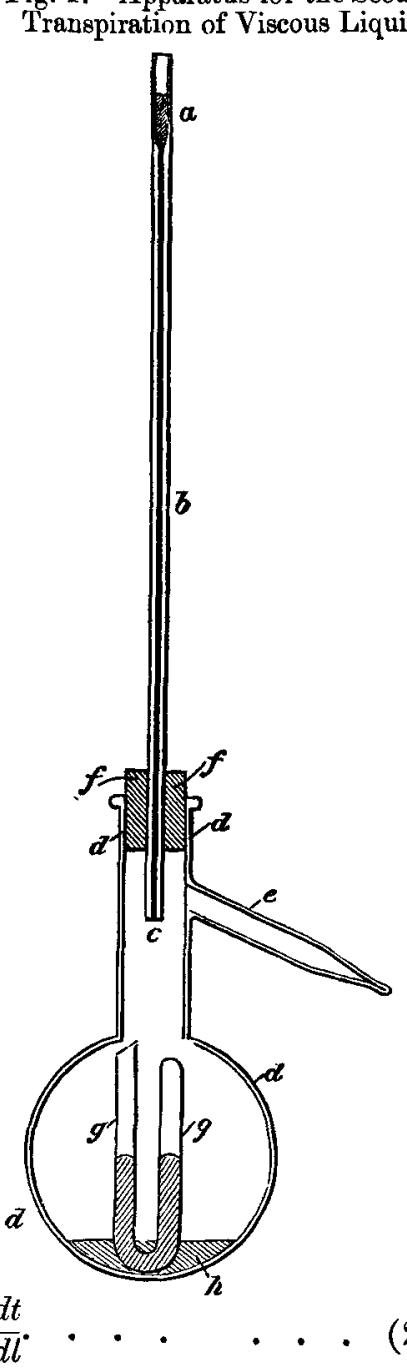

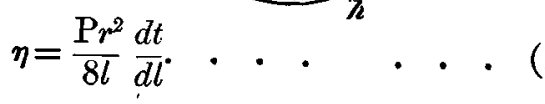

Integrating between 0 and $t$, and between $l_{1}$ and $l_{2}$,

$$
\eta=\mathrm{Pr}^{2} t / 4\left(l_{2}^{2}-l_{1}^{2}\right) \text {. . . . . }
$$

Here $l_{1}$ is the original length $(t=0)$, and $l_{2}$ the final length

* Pcgg. Ann. cix. p. 358 (1860). This reference is incidental, or I should have to refer to Poisson, Navier, Stokes, Stefan, Helmholtz, and
others. 


\section{$340 \mathrm{Mr}$. C. Barus on the Change of the Order of Absolute}

of the thread of marine glue. The effect of the cylinder of viscous fluid in the reservoir $a$ may be neglected from its large radius.

5a. By way of digression I may add another similar case; viz. that of a viscous liquid like glycerine, transpiring in a vertical capillary tube, in virtue of the weight of its own column only. In this case $\mathrm{P}=(\mathrm{L}+l) \delta g, \delta$ being the density of the liquid, $g$ the acceleration of gravity, $\mathrm{J}$ the initial head of the column. Inserting these quantities and integrating, equation (2) becomes

$$
\eta=\frac{\delta g r^{2}}{8\left(l_{2}-l_{1}+\mathrm{L} \ln \frac{\mathrm{L}+l_{1}}{\mathrm{~L}+l_{2}}\right)} t .
$$

An example of results obtained in this way is given in the following Table. The observations, though made upon a single descending thread at the end of each half minute, are grouped in two batches. The tube was dry ; perhaps a moist tube (adhering thin film of glycerine) would have been preferable.

$$
\begin{aligned}
& \text { Example.-Viscosity of Glycerine. } \\
& r=.0505 \text { centim.; } L=1 \cdot 35 \text { centim.; } \delta=1 \cdot 26 ; \Delta t=120 \text { sec. }
\end{aligned}
$$

\begin{tabular}{|c|c|c|c|c|c|}
\hline$t$ & $l$. & $\eta$ & $t$. & $l$. & $\eta$ \\
\hline $\begin{array}{r}\text { sec. } \\
30 \\
150 \\
60 \\
180 \\
90 \\
210 \\
120 \\
240\end{array}$ & $\begin{array}{c}\mathrm{cm} . \\
10 \cdot 07 \\
20 \cdot 30 \\
12 \cdot 72 \\
22 \cdot 75 \\
15 \cdot 30 \\
25 \cdot 10 \\
17 \cdot 80 \\
27 \cdot 43\end{array}$ & $\left\{\begin{array}{l}g / c s \\
505\end{array}\right.$ & $\begin{array}{l}\text { sec. } \\
270 \\
390 \\
300 \\
420 \\
330 \\
450 \\
360 \\
480\end{array}$ & $\begin{array}{c}\mathrm{cm} . \\
29 \cdot 82 \\
38 \cdot 60 \\
31 \cdot 95 \\
40 \cdot 83 \\
34 \cdot 20 \\
43 \cdot 04 \\
36 \cdot 40 \\
45 \cdot 22\end{array}$ & $\begin{array}{l}g / e s . \\
5 \cdot 53\end{array}$ \\
\hline
\end{tabular}

To account for the difference of $\eta$ in the two sets of results is beyond the present purpose. It is noteworthy * that each measurement of $\eta$ occupies but two minutes, even admitting that the tube is unfavourably wide; for in the case of viscous liquids the temperature-effect is of great importance, and this expeditious method therefore has some advantages. The experiment may be varied by observing the descending upper

* Cf. Graham, Phil. Trans. cli. p. 382 (1861):-_"The liquid (glycerine) is too viscous to be transpired by means of the bulb and capillary employed in these experiments." I am not aware that the viscosity has been measured since. 
Viscosity encountered on passing from Fluid to Solid. 341 meniscus, while the lower end of the capillary is submerged in glycerine.

6. By applying equation (3) I obtained the $\eta$ expressed in the following Table:-

$$
\begin{gathered}
\text { TABLE I.-Transpiration of Marine Glue. } \\
\mathrm{P}=10^{8} \text { dynes ; } r=\cdot 0406 \text { centim. ; temperatore (say) }=25^{\circ} .
\end{gathered}
$$

\begin{tabular}{|c|c|c|c|}
\hline Date. & $t$. & l. & $\eta \times 10^{-6}$. \\
\hline May $7,1889.12$ & ${ }_{0}$ & $\stackrel{\mathrm{em}}{\mathrm{em} .7}$ & $c / g s$ \\
\hline Dec. $7,1889,12$ & $18.5 \times 10^{8}$ & $7 \cdot 2$ & 200 \\
\hline
\end{tabular}

This is a striking result, remembering that a sphere of the cement, if placed on a plane surface, will run out to a flat cake in a few months. Nevertheless this type of viscous fluid is 20 billion times as viscous as water at the same temperature.

After long continued transpiration the thread of marine glue shows two strata. The advance portion is amher-coloured and less viscous, the rear portion brown, clearly containing most of the shellar. Hence the observed $\eta$ is probably somewhat low. (Cf. $\& 10$.

7. Paraffine (melting-point $55^{\circ}$ ) treated in the same way showed no transpiration. The tube $(2 \rho=082$ centim. $)$ was nearly of the same bore as above, and the length of thread in the most favourable case $2 \cdot 2$ centim. The motion, if any, must have been below 01 centim. Hence the viscosity of the paraffine must be greater than $2 \times 10^{11} \mathrm{~g} / \mathrm{cs}$ at about $25^{\circ}$. It is nearly impossible to insert a capillary paraffine thread in a tube, free from the vacuum-bubbles due to contraction on cooling.

\section{Solids.}

8. Having obtained the result in $\S 6, I$ proceeded to use it for obtaining the viscosity of hard steel by the method of comparison indicated in $\S 1$. The apparatus was essentially like that of my earlier experiments". To secure additional safety $\uparrow I$ introduced the principle of substitution, whereby the steel wire and the rod of marine glue were consecutively subjected to known torsion-couples, in ways otherwise identical. From the enormous viscosity of steel, as compared

* From the context it appears that the method of substitution is probably necessary.

$\dagger$ American Journal, xxxiv. p. 2 (1887).

Phil. Mag. S. 5. Vol. 29. No. 179. April 1890. 2 D 


\section{Mr. C. Barus on the Change of the Order of Absolute}

even with marine glue, a beam of this substance, say a decimetre thick, would show about the same deformation initially as a steel wire only a millimetre thick, cat. par. So large a mass of the cement is inconvenient to handle. I therefore used a rod about 4 centim. thick and suitably apportioned the torsion-couples in the two cases. The results are given in Tables II. and III., where $2 \rho$ is the diameter, $l$ the length, of the similarly twisted rods. This twist $\tau$ is given in the first column, and is proportional to the applied couples. $\mathrm{N}$ denotes the viscous motion at the index, at the time specified, and is given in scale-parts (distance between mirror and scale 200 centim.). Reduction of $\mathrm{N}$ is not necessary, since the present purposes are comparative. The steel wire is twisted alternately in opposite directions to allow for the accommodation. In Table II. this precaution is superfluous, the substance being a fluid. The three sets of data are merely given to show the behaviour more fully. Other experiments made with the cement may be omitted here.

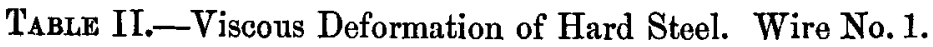
$\rho=0.40$ centim. ; $l=30$ centim.

\begin{tabular}{|c|c|c|c|c|c|c|c|c|}
\hline$\tau$ & Time. & $\mathrm{N} \times 10^{2}$ & $\tau$. & Time. & $\mathbf{N} \times 10^{2}$ & $\tau$. & Time. & $\mathrm{N} \times 10^{2}$ \\
\hline 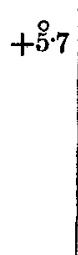 & $\begin{array}{c}\text { minutes. } \\
0 \\
2 \\
3 \\
4 \\
6 \\
8 \\
10 \\
12\end{array}$ & $\begin{array}{c}\text { cm. } \\
\text { Twisted. } \\
0 \\
70 \\
115 \\
187 \\
235 \\
278 \\
315\end{array}$ & $-\stackrel{\circ}{5} \cdot 7$ & $\begin{array}{c}\text { minutes. } \\
0 \\
2 \\
3 \\
4 \\
6 \\
8 \\
10 \\
12\end{array}$ & $\begin{array}{c}\text { cm. } \\
\text { Twisted. } \\
-\quad 0 \\
-71 \\
-125 \\
-200 \\
-258 \\
-301 \\
-340\end{array}$ & $+\stackrel{\circ}{5} 8$ & $\begin{array}{c}\text { minutes. } \\
0 \\
2 \\
4 \\
3 \\
6 \\
8 \\
10 \\
12\end{array}$ & $\begin{array}{c}\text { om. } \\
\text { Twisted. } \\
0 \\
40 \\
72 \\
122 \\
160 \\
190 \\
212\end{array}$ \\
\hline
\end{tabular}

TABLE III.-Viscous Deformation of Marine Glue. $\rho=2$ centim. ; $l=30$ centin.

\begin{tabular}{|c|c|c|c|c|c|c|c|c|}
\hline T. & Time. & $\mathbf{N} \times 10^{2}$ & T. & Time. & $\mathrm{N} \times 10^{2}$ & t. & Time. & $\mathbf{N} \times 10^{2}$ \\
\hline *i·4 & $\begin{array}{c}\text { minutes. } \\
0 \\
2 \\
3 \\
4 \\
5\end{array}$ & $\begin{array}{r}\mathrm{cm}_{0} \\
0 \\
260 \\
480 \\
710 \\
910\end{array}$ & $\stackrel{0}{1.4}$ & $\begin{array}{c}\text { minutes. } \\
\mathbf{0} \\
\mathbf{2} \\
\mathbf{3} \\
\mathbf{4} \\
\mathbf{5}\end{array}$ & $\begin{array}{r}\text { em. } \\
\text { o } \\
250 \\
450 \\
700 \\
900\end{array}$ & $i \cdot 4$ & $\begin{array}{c}\text { minutes. } \\
0 \\
2 \\
3 \\
4 \\
5 \\
6\end{array}$ & $\begin{array}{r}\mathrm{cm} . \\
0 \\
220 \\
420 \\
610 \\
810 \\
1010\end{array}$ \\
\hline
\end{tabular}

* This refers to the applied couple. The initial twist of the bar of marine glue is practically zero. 
9. From these Tables the mean rate of motion of marine glue appears as 2 centim. per minute, whereas the corresponding mean motion for hard steel is (say*) $\cdot 4$ centim. per minute, for the three cases. The couple acting on the cement is $1.4 x$, while the couple in the other case is $5 \cdot 7 x$. Since the cement is a fluid, the rate of motion for identical couples would be 8 centim.

The principle given in $\$ 1$ may now be applied, whereby viscosities are inversely as the fourth power of the radii, cat. par. Let $\eta^{\prime}$ and $\eta$ be the viscosities of marine glue and bard steel respectively. Then

$$
\eta=\eta^{\prime}\left(\frac{2 \cdot 00}{\cdot 04}\right)^{4} \frac{8 \cdot 0}{\cdot 4}=\eta^{\prime} \times 10^{9} / 8 . \quad . \quad . \quad .
$$

From Table I., $\eta^{\prime}=200 \times 10^{6}$; hence the mean viscosity of originally untwisted glass-hard steel, during three consecutive alternate twists of 12 minutes each, just within the limits of rupture is at least

$$
\eta=25 \times 10^{15} \mathrm{~g} / \mathrm{sc} . \text {. . . . . }
$$

10. The present results subserve their chief purpose in furnishing an estimate of the order of viscosity of glass-hard steel ; for the unavoidable errors encountered in a comparative method like the present are not insignificant. In the first place the thread of marine glue observed for transpiration in $\$ 6$ during half a year is not identical with the rod of this material which is twisted $(\S 8)$, neither as to temperature nor composition ( $c f$. remarks end of $\S 6$ ). Possibly better results might be obtained with old pitch. Again, the rod of marine glue, while it is being twisted, is also being appreciably stretched by its own weight. This complicates the angular measurement. Finally, the sectional error of an opaque rod, not necessarily free from air-bubbles, is considerable. Equation (3) must therefore be looked on as assigning an order to the viscosity of hard steel above $10^{16} \mathrm{~g} / \mathrm{cs}$.

11. Before giving the results of the following direct method, it is expedient to insert a paragraph on the viscosity of solids generally. In $\S 8$, while the steel wire is strained by the couple almost as far as the limits of elasticity permit, the rod of marine glue is initially scarcely strained at all. In the latter case, however, the unstable configurations essential to viscous motion are supplied in relatively great numbers by the ever changing distribution of the heat-agitation within the body. In a homogeneous solid free from strain (soft steel)

* The viscosity of solids being a function of time, strain, and temperature. This distinction is beyond the purposes of the above paragraph, but will be fully carried out below, in $\$ \$ 11$ et seq. 


\section{Mr. C. Barus on the Change of the Order of Absolute}

such configurations practically vanish as to number. I doubt whether in soft steel the viscons deformation due to instantaneous exceptionally interse moleoular motion at different points within the solid, could be recognized at ordinary temperatures. The case is different when the solid is under stress. Any twist, no matter how small (?), is accompanied by a proportionate amount of permanent strain, with which a corresponding amount of instability is necessarily associated. Hence it mast be borne in mind that the viscosities expressed absolutely below refer to steel in a condition of strain just within the elastic limits.

I can here merely allude to the very recent and suggestive paper of C..H. Carus-Wilson (Nature, xli. p. 213, 1890), in which the behaviour of steel near the elastic limits is interpreted in analogy with the well-known eircumflexed isothermals of condensible gases, due to James Thomson.

Now it is clear that if stressed steel be left to itself, the number of unstable configurations becomes rapidly less as the time after twisting increases. Energy is dissipated. The viscosity of solids is therefore essentially a time-function as well as a strain-function.

12. The apparatus with which the following absolute results

Fig. 2. - A pparatus for measuring the Absolute Viscosity of Solids.

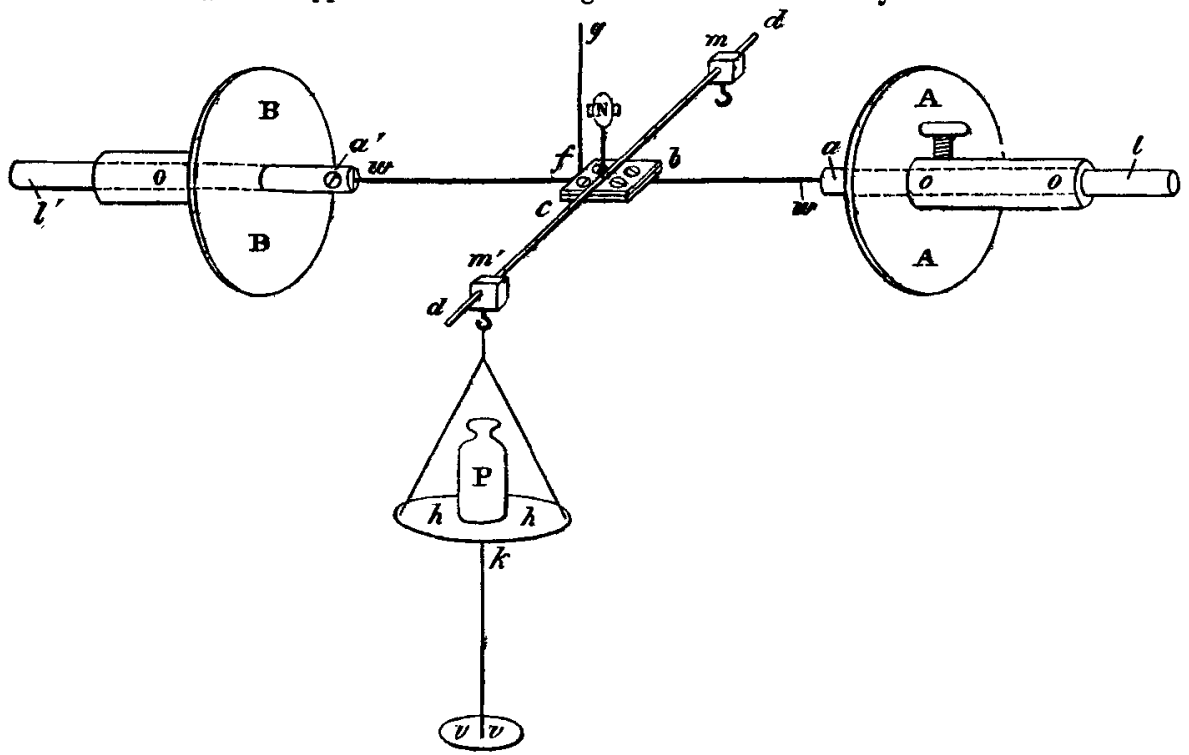

were obtained is shown in fig. 2, A A and B B are two massive torsion-circles, the hollow eylindrical shafts, $a o$, of 
Viscosity encountered on passing from Fluid to Solid. 345

which are firmly clamped to supports projecting from the wall of the room. The steel wire, $w w$, to be tested is tensely drawn between the cylindrical cores, $a l, a^{\prime} l^{\prime}$, and clamped without torsion. To accomplish this the ends of the wire are bent hook-shaped, and inserted in flat fissures at the ends of the rods $a l, a^{\prime} l^{\prime}$, the clamp-screw (shown at $a^{\prime}$ ) passing through the hooks of the wire. The middle part of $w w$ carries a pair of plates, $b c$, held together by four screws in such a way as to clamp the wire firmly between the plates. A brass rod of screw-wire, $d d$, is soldered to the upper plate, and when in adjustment is horizontal and at right angles to the axis of $w w$. Thus the rod $d d$ is virtually the beam of a balance, and two small nuts, $m m^{\prime}$, symmetrically placed near the ends of $d d$, are provided with hooks from which a scalepan, $h h$, may be suspended. The latter carries a light horizontal disk, $v v$, to be submerged in water (not shown), with the object of deadening vibrations when the apparatus is in adjustment. The upper plate $b c$ also carries an adjustable mirror, $\mathrm{N}$, for angular measurement, as well as an index, $f g$, moving across a stationary graduated dial (not shown) by which the amount of twist holding the weight, $P$, in equilibrium is roughly registered.

In adjusting the apparatus, the scale-pan $h h$ is removed and the rods $a l$ so placed that the lever $d d$ is vertical. After clamping a $l$ (care being taken to avoid twisting $w w$ ) the scale-pan is attached at $m^{\prime}$, and additional weights $\mathrm{P}$ added to hold the lever $d d$ horizontal. Hence the two halves of the wire $w w$ are twisted $90^{\circ}$ each for the whole length. Other twists may be applied by rotating the torsion-circles together (it would be necessary to connect them rigidly for this purpose) and adding suitable weights $P$.

To fasten the wire securely between the plates the lower one is clamped horizontally in a vice. If there were rotational sliding possible here it would be detected in examining very viscous wires. Some difficulty is experienced in fixing $w w$ in place quite free from initial torsion. There is also some flexure; but for wires of the radius given these discrepancies may be disregarded. When $A A$ and $B$ B are rigidly connected, the twist of the wire $w w$ may be expressed in terms of the load $P$.

13. To complete the results obtained with this apparatus, let $2 \phi$ be the amount of angular viscous motion *, in radians, of any right section of the wire relative to another right section, whose distance from the first is the unit of length. Suppose, furthermore, that in the plane of a right section

- The factor 2 is supplied conformably with my earlier notation. 


\section{Mr. C. Barus on the Change of the Order of Absolute}

there is no shearing. Then $2 d \phi / d t=2 \mathrm{C}_{t}$ is the common angular velocity, per unit of length, with which the shear is increased. Consider an elementary cylindrical shell whose length $l$ is the effective length of either half of the wire $w . w$ (fig. 2), and whose right section is $2 \pi r d r$. Then the amount of force distributed uniformly over $2 \pi r d r$ will be

$$
d f=\eta_{t} \frac{2 \pi r d r}{\iota}\left(l 2 \mathrm{C}_{t} r\right) . . . . .
$$

Multiplying by $r$, and integrating between 0 and $\rho$, the radius of the steel wire,

$$
\frac{1}{2} \mathrm{P} \lambda=\eta \frac{\pi \rho^{4}}{2} \mathrm{ZC}_{t}, \quad . \quad . \quad . . .
$$

where $\mathrm{P} / 2$ is the weight at the end of the lever-arm $\lambda$, per effective half of the wire. In any given adjustment $P \lambda / \pi \rho^{4}=A$ $=$ constant. Hence

$$
\eta_{t}=\mathrm{A} / 2 \mathrm{C}_{t} \text {. . . . . . . }
$$

In these equations it has been assumed that $\int \eta r^{3} d r=\eta_{t} \int r^{3} d r$. Hence under all circumstances $\eta_{t}$ is a mean value defined by these integrals.

14. Results obtained with the apparatus $\S 12$, are given in Tables IV. to VII. Here $\rho$ is the radius, $l$ the length of each effective half of the steel wire. $P$ is the total force (being the weight plus the weight of the scale-pan) acting at the end of the lever $\lambda$ (see fig. 2). The rate of twist is given under $\tau$, and $2 \Phi$ is the total yield during the interval of experiment. $\mathrm{N}$ denotes the actual scale-reading observed by the telescope (scale-distance from mirror, $R=200$ centim.) at the time given; and $2 \phi$ is the viscous angular motion between two right sections of the steel wire 1 centim apart.

In the second half of the tables, $2 \mathrm{C}_{t}$ is the time-rate of change of $2 \phi$, computed for consecutive intervals of 500 seconds each. The final column contains the corresponding absolute viscosity. All times are reckoned from the moment of twisting. To obtain $2 \mathrm{C}_{t} \mathrm{I}$ availed myself of graphic methods *, these being in conformity with the mean accuracy of the work. Table IV. contains results for the wire No. 1, already tested in Table I. Three twists are applied, alternately in opposite directions. In Table V. the same wire is similarly examined, after it has been softened by heating to

- Of course a set of smoother values might be obtained by computing the constants of the curves $\phi$ from Kohlrausch's exponential formula, and the tangents fiom the values obtained. 
Viscosity encountered on passing from Fluid to Solid. 347 redness and cooling in air. Table VI. contains data for a new glass-hard steel wire, originally free from stored twist. Table VII., finally, contains the viscous behaviour of a wire tempered at $450^{\circ}$, which was used as a normal in my former differential experiments.

TABLE IV.-Absolnte Viscosity of a Glass-hard Steel Wire. No. 1. Fourth Twist.

$l=12 \cdot 9$ centim.; $\rho=\cdot 0405$ centim. ; $\mathrm{P}=82 \times 981$ dynes; $\lambda=9 \cdot 43$ centim.

\begin{tabular}{|c|c|c|c|c|c|c|}
\hline$\stackrel{\tau}{\boldsymbol{T}} \dot{\Phi}$. & Time. & $\mathrm{N} \times 10^{2}$ & $2 \phi \times 10^{6}$ & Time. & $2 \mathrm{C}_{t} \times 10^{9}$ & $\eta_{t} \times 10^{-15}$ \\
\hline $\begin{array}{l}\text { Radians. } \\
\qquad \cdot 12\end{array}$ & $\begin{array}{r}\text { Sec. } \\
0 \\
420 \\
720 \\
1020 \\
1860 \\
2220 \\
2820 \\
3480\end{array}$ & $\begin{array}{c}\text { Centim. } \\
\text { Twisted. } \\
0 \\
104 \\
180 \\
320 \\
360 \\
417 \\
465\end{array}$ & $\begin{array}{c}\text { Radians per } \\
\text { centim. } \\
\text { *0 } \\
202 \\
349 \\
621 \\
698 \\
808 \\
901\end{array}$ & $\begin{array}{r}\text { Sec. } \\
0 \\
500 \\
1000 \\
1500 \\
2000 \\
2500 \\
3000\end{array}$ & $\begin{array}{c}\text { Radians } \\
\text { per centim. } \\
\text { per sec. } \\
\\
735 \\
462 \\
310 \\
222 \\
183 \\
150\end{array}$ & $\begin{array}{l}g / c s . \\
\\
122 \\
194 \\
291 \\
405 \\
491 \\
600\end{array}$ \\
\hline \multicolumn{7}{|c|}{ No. 1. Glass-hard. } \\
\hline $\begin{array}{r}-\cdot 12 \\
-009\end{array}$ & $\begin{array}{r}0 \\
480 \\
840 \\
1320 \\
1860 \\
2400 \\
2940 \\
3480\end{array}$ & $\begin{array}{c}\text { Twisted. } \\
* 0 \\
120 \\
235 \\
329 \\
402 \\
464 \\
520\end{array}$ & $\begin{array}{r}{ }^{* 0} 0 \\
233 \\
456 \\
638 \\
779 \\
900 \\
1008\end{array}$ & $\begin{array}{r}0 \\
500 \\
1000 \\
1500 \\
2000 \\
2500 \\
3000\end{array}$ & $\begin{array}{r}* 910 \\
474 \\
347 \\
270 \\
230 \\
210\end{array}$ & $\begin{array}{r}99 \\
190 \\
259 \\
333 \\
391 \\
428\end{array}$ \\
\hline \multicolumn{7}{|c|}{ No. 1. Glass-hard. Sixth Twist. } \\
\hline $\begin{array}{r}.12 \\
-.009\end{array}$ & $\begin{array}{r}0 \\
360 \\
960 \\
1260 \\
1800 \\
2340 \\
3120 \\
3900\end{array}$ & $\begin{array}{c}\text { Twisted. } \\
0 \\
120 \\
160 \\
210 \\
250 \\
306 \\
353\end{array}$ & $\begin{array}{r}0 \\
233 \\
310 \\
407 \\
485 \\
593 \\
684\end{array}$ & $\begin{array}{r}0 \\
500 \\
1000 \\
1500 \\
2000 \\
2500 \\
3000\end{array}$ & $\begin{array}{l}467 \\
265 \\
193 \\
156 \\
138 \\
126\end{array}$ & $\begin{array}{l}193 \\
339 \\
466 \\
577 \\
652 \\
715\end{array}$ \\
\hline
\end{tabular}

* The minus signs, being without interest in this and the following similar series, are omitted for brevity. 
348 Mr. C. Barus on the Change of the Order of Absolute

Tabiz V.-Absolute Viscosity of Soft Steel, being Wire

No. 1, heated to redness and cooled in air. First Twist.

$l=13.0$ centim.; $\rho=\cdot 0405$ centim. ; $P=82 \times 981$ dynes; $\lambda=9^{\cdot} 43$ centim.

\begin{tabular}{|c|c|c|c|c|c|c|}
\hline $2 \dot{\varphi} \dot{\phi}$. & Time. & $\mathrm{N} \times 10^{2}$ & $2 \phi \times 10^{8}$ & Time. & $20, \times 10^{9}$ & $\eta_{t} \times 10^{-15}$ \\
\hline $\begin{array}{c}\text { Radians. } \\
\cdot 12 \\
-.007\end{array}$ & $\begin{array}{r}\text { Bec. } \\
0 \\
420 \\
900 \\
1500 \\
2100 \\
2700 \\
3380 \\
3780\end{array}$ & \begin{tabular}{|r|} 
Centim. \\
Twisted. \\
0 \\
40 \\
63 \\
80 \\
92 \\
98 \\
103
\end{tabular} & $\begin{array}{c}\text { Radians } \\
\text { per centim. } \\
0 \\
77 \\
121 \\
154 \\
177 \\
188 \\
198\end{array}$ & $\begin{array}{r}\text { Sec. } \\
0 \\
500 \\
1000 \\
1500 \\
2000 \\
2500 \\
3000\end{array}$ & \begin{tabular}{|c|} 
Radians \\
per centim. \\
per sec. \\
220 \\
220 \\
89 \\
63 \\
47 \\
34 \\
26
\end{tabular} & $\begin{array}{r}g / c 8 . \\
\\
409 \\
1010 \\
1430 \\
1920 \\
2650 \\
3460\end{array}$ \\
\hline \multicolumn{7}{|c|}{ No. 1. Softened. } \\
\hline $\begin{array}{r}-\cdot 12 \\
\cdot 010\end{array}$ & $\begin{array}{r}0 \\
360 \\
1020 \\
1500 \\
1983 \\
2520 \\
\mathbf{3 1 2 0}\end{array}$ & $\begin{array}{c}\text { Twisted. } \\
0 \\
50 \\
70 \\
82 \\
93 \\
100\end{array}$ & $\begin{array}{r}0 \\
96 \\
135 \\
158 \\
179 \\
192\end{array}$ & $\begin{array}{r}0 \\
500 \\
1000 \\
1500 \\
2000 \\
2500 \\
3000\end{array}$ & $\begin{array}{r}164 \\
116 \\
59 \\
40 \\
30 \\
15\end{array}$ & $\begin{array}{r}550 \\
776 \\
1520 \\
2250 \\
3000 \\
6000\end{array}$ \\
\hline \multicolumn{7}{|c|}{ No. 1. Softened. } \\
\hline $\begin{array}{r}.12 \\
-.007\end{array}$ & $\begin{array}{r}0 \\
240 \\
840 \\
1560 \\
2100 \\
2520 \\
2640 \\
3120\end{array}$ & \begin{tabular}{|c|} 
Twisted. \\
0 \\
42 \\
64 \\
74 \\
76 \\
78 \\
81
\end{tabular} & $\begin{array}{r}0 \\
81 \\
123 \\
142 \\
146 \\
150 \\
156\end{array}$ & $\begin{array}{r}0 \\
200 \\
1000 \\
1500 \\
2000 \\
2500 \\
3000\end{array}$ & $\begin{array}{r}138 \\
70 \\
40 \\
28 \\
17 \\
14\end{array}$ & $\begin{array}{r}652 \\
1290 \\
2250 \\
3210 \\
5300 \\
6400\end{array}$ \\
\hline
\end{tabular}


Viscosity encountered on passing from Fluid to Solid. 349

TABLE VI.-Absolute Viscosity of Glass-hard Steel. Wire No. 2. First Twist.

$l=13.0$ centim.; $\rho=\cdot 0405$ centim. ; $\mathrm{P}=82 \times 981$ dynes; $\lambda=9 \cdot 43$ centim.

\begin{tabular}{|c|c|c|c|c|c|c|}
\hline$\stackrel{7 .}{2 \dot{\Phi}}$ & Time. & $\mathrm{N} \times 10^{2}$, & $2 \beta \beta \times 10^{6}$ & Time. & $2 C^{t} \times 10^{8}$ & $n_{t} \times 10^{-1}$ \\
\hline $\begin{array}{c}\text { Radians. } \\
-.009 \\
-.09\end{array}$ & $\begin{array}{r}\text { Sec. } \\
0 \\
120 \\
420 \\
720 \\
1030 \\
1620 \\
2100 \\
2580 \\
3000\end{array}$ & $\begin{array}{c}\text { Oentim. } \\
\\
\text { Twisted. } \\
0 \\
186 \\
270 \\
335 \\
410 \\
458 \\
495 \\
518\end{array}$ & $\begin{array}{c}\text { Radians } \\
\text { per centim. } \\
\\
0 \\
358 \\
520 \\
644 \\
789 \\
881 \\
952 \\
996\end{array}$ & $\begin{array}{r}\text { Soc. } \\
0 \\
500 \\
1000 \\
1500 \\
2000 \\
2500\end{array}$ & $\begin{array}{c}\text { Radians } \\
\text { per centim } \\
\text { per sec. } \\
\\
660 \\
325 \\
230 \\
180 \\
140\end{array}$ & $\begin{array}{l}g / c s . \\
\\
136 \\
277 \\
391 \\
500 \\
643\end{array}$ \\
\hline
\end{tabular}

No. 2. Glass-hard. Second Twist.

\begin{tabular}{l|r|r|r||r|r|r}
$-\cdot 13$ & 0 & Twisted. & & 0 & & \\
-010 & 240 & 0 & 0 & 500 & 683 & 131 \\
& 600 & 144 & 277 & 1000 & 392 & 229 \\
& 900 & 220 & 423 & 1500 & 285 & 316 \\
& 1260 & 288 & 554 & 2000 & 240 & 375 \\
& 1800 & 365 & 702 & 2500 & 205 & 439 \\
& 2100 & 404 & 777 & & & \\
& 2460 & 450 & 865 & & & \\
& 2700 & 470 & 904 & & & \\
& 3000 & 502 & 965 & & & \\
\hline
\end{tabular}

No. 2. Glass-hard. Third Twist.

\begin{tabular}{|r|r|r|}
\hline 0 & Twisted. & 0 \\
240 & 0 & 0 \\
600 & 117 & 225
\end{tabular}||||||


TABLE VII.-Absolute Viscosity of Steel, annealed at $450^{\circ}$. Wire No. 15. Twisted indefinitely.

$l=13.6$ centim.; $\rho=0405$ centim. ; $\mathrm{P}=82 \times 981$ dynes; $\lambda=9 \cdot 43$ centim.

\begin{tabular}{|c|c|c|c|c|c|c|}
\hline $2^{\top} \dot{\Phi}$. & Time. & $\mathbf{N} \times 10^{2}$ & $2 \phi \times 10^{6}$ & Tinne. & $2 \mathrm{C}_{t} \times 10^{9}$ & $\eta_{t} \times 10^{-15}$ \\
\hline $\begin{array}{r}\text { Radians. } \\
-12 \\
-.002\end{array}$ & $\begin{array}{r}\text { Sec. } \\
0 \\
0 \\
240 \\
720 \\
1200 \\
1860 \\
2520 \\
2000\end{array}$ & \begin{tabular}{|c|} 
Centim. \\
\\
Twisted. \\
0 \\
51 \\
71 \\
86 \\
95 \\
101
\end{tabular} & $\begin{array}{c}\text { Radians } \\
\text { per centim. } \\
\\
0 \\
94 \\
131 \\
158 \\
175 \\
186\end{array}$ & $\begin{array}{r}\text { Sec. } \\
0 \\
500 \\
1000 \\
1500 \\
2000 \\
2500 \\
3000\end{array}$ & \begin{tabular}{|c|}
$\begin{array}{c}\text { Radians } \\
\text { per centim. } \\
\text { per sec. }\end{array}$ \\
177 \\
69 \\
40 \\
32 \\
25 \\
20
\end{tabular} & $\begin{array}{r}508 \\
1300 \\
2250 \\
2810 \\
3600 \\
4500\end{array}$ \\
\hline
\end{tabular}

No. 15. Tempered at $450^{\circ}$. Next Twist.

\begin{tabular}{|r|r|r|r|r|r|r|}
\hline$\cdot 12$ & 0 & Twisted. & & 0 & & \\
.003 & 240 & 0 & 0 & 500 & 111 & 811 \\
& 600 & 26 & 48 & 1000 & 46 & 1950 \\
& 1200 & 43 & 80 & 1500 & 40 & 2250 \\
& 1740 & 54 & 100 & 2000 & 34 & 2650 \\
& 2580 & 68 & 125 & 2500 & 31 & 2910 \\
& 3240 & 81 & 149 & 3000 & 30 & 3000 \\
\hline
\end{tabular}

No. 15. Tempered at $450^{\circ}$. Next Twist.

\begin{tabular}{r|r|r|r|r|r|r}
\hline$\cdot 12$ & 0 & Twisted. & & 0 & & \\
-.003 & 240 & 0 & 0 & 500 & 180 & 500 \\
& 660 & 48 & 88 & 1000 & 82 & 1100 \\
& 1260 & 78 & 143 & 1500 & 57 & 1570 \\
& 1740 & 92 & 169 & 2000 & 48 & 1870 \\
& 2520 & 112 & 206 & 2500 & 45 & 2000 \\
& 3120 & 126 & 232 & 3000 & 42 & 2140 \\
\hline
\end{tabular}

Some irregularities are apparent, largely introduced by vibrations against which our laboratory facilities afford no adequate protection. Vibrations increase the rate of twist 
periodically, and thus supply a greater number of instabilities than correspond to the mean twist (position of equilibrium) in question. They may also have a more direct molecular effect in decreasing viscosity. When the rate of twist in the two wires is unequal, viscous motion will also be in excess of the true value. This also applies in case of slightly different lengths, $l$, of the two effective halves of the wire. In the case of No. 15, which had become somewhat worn by use, the load $\mathrm{P}$ probably strained the wire too near the elastic limits. This I infer from the observed successive reduction of viscosities from twist to twist, clearly indicating that an excess of instability is being supplied. It is therefore better to accept the behaviour of No. 2 (soft) as typical of No. 15; for the normal viscosities of the two states of temper are identical.

\section{Discussion.}

15. Turning first to the values of $\phi$, it is seen at once that they substantiate the interences of my earlier papers throughout*. They therefore need no further comment bere. Tables V., VII. contain data for my normal wire, by aid of which the differential results of the earlier papers may be reduced to absolute values. I have endeavoured to make the angles $\tau$ of nearly the same value in all cases, so that $\phi / \tau$ may be comparable.

16. The spontaneous breaking of the glass-hard wire in Table VI. deserves mention. It occurred during the third twist, and at a time when the wire was in no way interfered with. This corresponds to the spontaneous explosion of hard projectiles frequently observed. It also corresponds to the spontaneous rupture of stressed glass, whether the stress be stored internally or applied externally. I have observed this interesting phenomenon in glass under a great variety of

* Phil. Mag. xxvi. p. 183 (1888); ibid. xxvii. p. 155 (1889).

In the deductions of the former paper (p. 189) I neglected the elastic motion, in virtue of which, at every stage of viscous yielding, the rate of twist is maintained constant throughout the system. After correcting for this,

$$
\mathrm{L} \psi=2 l^{\prime}\left\{\phi_{3}\left(\beta-l^{\prime}\right)+\phi(a-\beta)+\phi_{1}(\mathrm{~L}-a)\right\}-2 l \phi^{\prime} l^{\prime} ;
$$

which under the simplified conditions of experiment becomes $\psi=l\left(\phi-\phi^{\prime}\right)$. Hence it follows that the data $\left(\phi-\phi^{\prime}\right)$ of the two papers cited are relative, and must be multiplied by $\ln 2$ to reduce them to the dimensions defined in the text. Beyond this the error is without importance, the data applying at once to rods initially somewhat harder than those actually observed. 


\section{Mr. C. Barus on the Change of the Order of Absolute}

conditions. In all cases there is gradnal molecular change, and the solid finally breaks without any apparent cause.

17. The chief results of Tables IV. to VII. are the values $\eta_{t}$, whether they be regarded as time-functions, or as exponents of the solidity of steel. In fig. 3 these data are constructed graphically. An inspection of the figure shows at once that both solid viscosity and its rate of increase with time are magnitudes which increase together (Tables IV., VI. compared with Tables V., VII.). After about an hour has elapsed since twisting, the viscosity of hard steel may be quite as large as the initial viscosity of soft steel ; but at corresponding times the viscosity of soft steel continues to be more and more pronouncedly the greater.

The curves are not consistent as to curvature. This may be best inferred from the hard wires, where the viscosities are smaller, the deformations large, and the observations therefore as a whole much more accurate (Tables IV., VI.). Hence I regard the promiscuous irregularities of fig. 3 as due to errors of observation and construction. According to the law of $\mathrm{F}$. Kohlrausch $*,-d \phi / d t=a \phi / t_{n}$, where $a$ and $n$ are constants. In case of small torsions or short times, $-d \phi / d t$ $=\alpha \phi / t$ suffices. Thus for the purpose of deducing the timerates, $\kappa$, of increase of solid viscosity, it is permissible to regard the curves of fig. 3 as essentially linear.

This is done in the following table.

TABLE VIII.-Mean time-rate of increase of the absolute Viscosity of Steel, hard and soft.

\begin{tabular}{|c|c|c|c|c|c|}
\hline \multicolumn{3}{|c|}{ Hard Steel. } & \multicolumn{3}{|c|}{ Soft Steel. } \\
\hline & Twist No. & $x \times 10^{-12}$. & & Twist No. & $k \times 10^{-12}$ \\
\hline Table VI... & $\begin{array}{r}4 \\
-\mathbf{5} \\
6 \\
1 \\
-2\end{array}$ & $\begin{array}{l}g / \mathrm{cs}^{2} \\
220 \\
140 \\
240 \\
230 \\
140\end{array}$ & $\begin{array}{l}\text { Table V... } \\
\text { Table VII. }\end{array}$ & $\begin{array}{r}1 \\
-2 \\
3 \\
1 \\
-2 \\
3\end{array}$ & $\begin{array}{l}g / 08^{2} \\
1200 \\
1400 \\
1900 \\
1500 \\
1200 \\
1000\end{array}$ \\
\hline \multicolumn{3}{|c|}{$\begin{array}{l}\text { Mean rate } x \ldots \ldots \ldots \ldots . \ldots 194 \times 10^{12} \\
\text { Mean viseosity at } 500 \text { sec. } 140 \times 10^{15}\end{array}$} & \multicolumn{3}{|c|}{$\begin{array}{l}\text { Mean rate } x \ldots \ldots \ldots \ldots . .1400 \times 10^{18} \\
\text { Mean viscosity at } 500 \text { sec } 570 \times 10^{10}\end{array}$} \\
\hline
\end{tabular}

* Kohlrausch, Pogg. Ann. exxviii. p. 216 (1866). 
Viscosity encountered on passing from Fluid to Solid. 353

Fig. 3. -The Absolute Viscosity of Hard Steel (Tables TV., VI.) and of Soft Steel (Tables V., VII.), considered in its variation with the time elapsing after twisting.

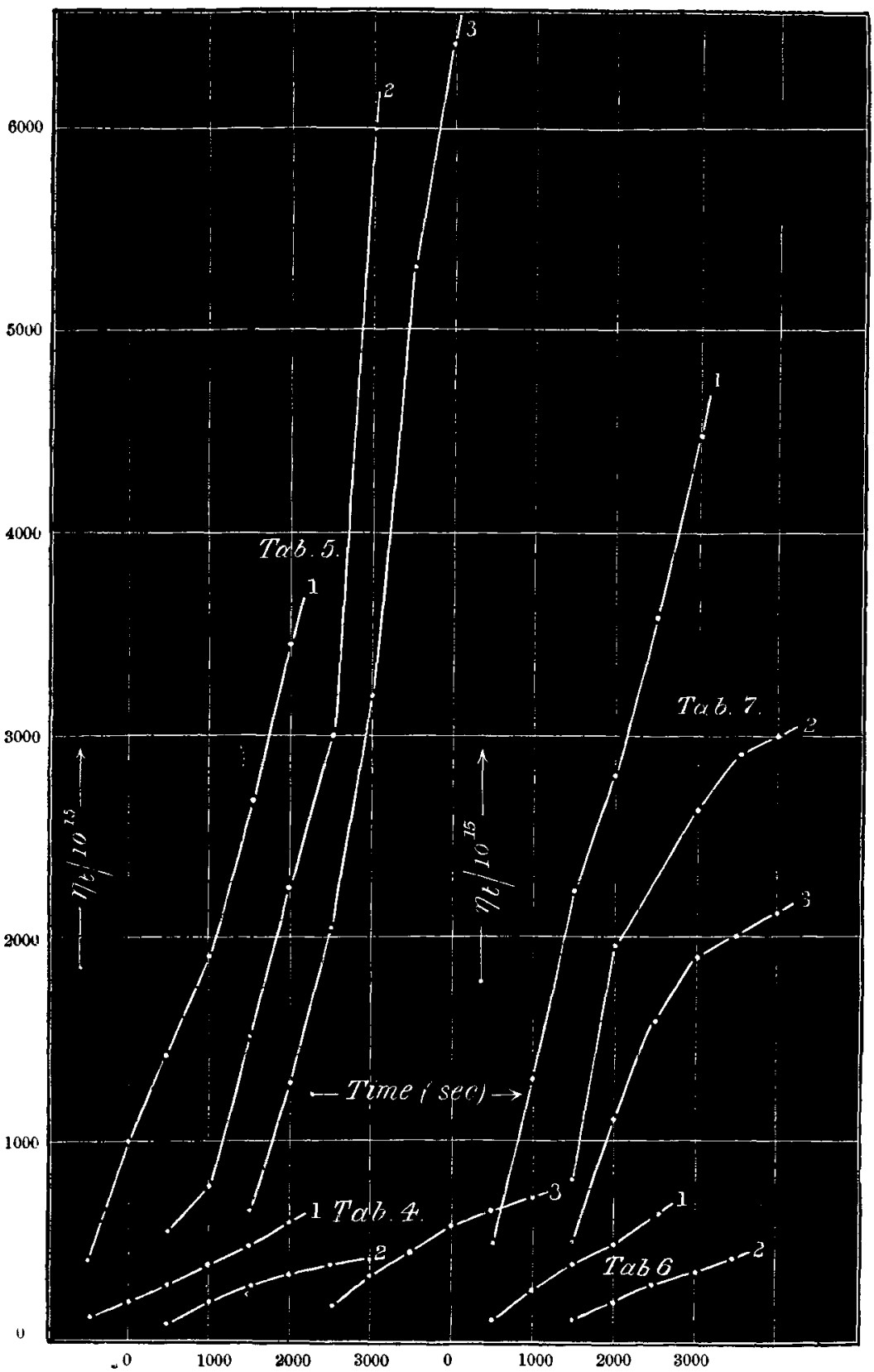


The general explanation of these results has been indicated in $\$ 11$. In a liquid or a viscous fluid under moderate stress the instabilities are supplied by the mere thermal agitation at ordinary temperatures, at the same rate in which they are used in promoting viscous motion. Hence viscosity is constant at a given temperature. In a solid under stress the instabilities are expended-at a rate decidedly greater than the small rate of continuous supply. Thus viscosity decidedly inincreases with time. Suppose, therefore, a solid of initially greater viscosity starts on its viscous deformation at an instant when the viscosity of a solid of initially smaller viscosity has been increased by time to the initial value of the former case. This can actually be realized by twisting a soft steel rod about an hour later than a hard steel rod (fig. 3). Then, in succeeding times, even though the substances sturt at a state where both are equally viscous, the viscosity of the initially more solid body will rapidly overtake the other; for the supply of instability due to temperature alone is continuously greater in one case than in the other.

18. Summarizing the results of the above paragraphs, the viscosities of the three states of aggregation may be expressed in terms of the absolute $\mathrm{g} / \mathrm{cs}$ scale as follows:-

TABLE IX.-Viscosity, considered in its Variations with the State of Aggregation.

\begin{tabular}{|c|c|c|c|c|c|}
\hline \multicolumn{2}{|c|}{ Gases and Vapours. } & \multicolumn{2}{|c|}{$\begin{array}{c}\text { Andrews's } \\
\text { critical state. }\end{array}$} & \multicolumn{2}{|c|}{$\ddagger$ Liquids. } \\
\hline Substance. & $\eta$ & $\begin{array}{l}\text { Sub- } \\
\text { stance. }\end{array}$ & $\eta$. & Substance. & $\eta$. \\
\hline * Ether, 0 & $6.8 \times 10^{-5}$ & ? & P & Ether, 30. & $9 \times 10^{-4}$ \\
\hline$* \mathbf{H}_{2}, \quad 0$ & $8.7 \times 10^{-5}$ & & & Ether, $10 .$. & $1.9 \times 10^{-3}$ \\
\hline * Air, $\quad 0$ & $1.75 \times 10^{-4}$ & & & Water, 97 .. & $3.0 \times 10^{-3}$ \\
\hline$+o_{r} \quad 0$ & $2 \cdot 12 \times 10^{-4}$ & & & Water, 20 .. & $1.0 \times 10^{-2}$ \\
\hline & & & & \& Glycerine... & 5 \\
\hline Range ......... & $10^{-5}$ to ? & $?$ & to? & Range ..... & ? to $10^{-2}$ \\
\hline
\end{tabular}

* Puluj, l.c.

† O. F. Meyer, l. c. p. 142.

† Landolt and Boernstein's Tables, l. c., and Slotte, l.c.

8 A rough measurement of my own, \$5a. Graham's results, Phil. Trans 1861, p. 373, refer to dilute glycerine. 
Table IX. (continued).

\begin{tabular}{|c|c|c|c|}
\hline \multicolumn{2}{|c|}{ Viscous Fluids. } & \multicolumn{2}{|l|}{ Solids. } \\
\hline Substance. & $\eta$ & Substance. & $\eta$ \\
\hline Marine glue .......... & $2 \times 10^{9}$ & $\begin{array}{l}\begin{array}{l}\text { Paraffine at } 20^{\circ} \text { (m.p. } \\
\left.55^{\circ}\right) .\end{array} \\
+ \text { Hard steel, glass \&c. } \\
\text { † Soft steel ............... }\end{array}$ & $\begin{array}{l}>2 \times 10^{11} \\
\left\{\begin{array}{l}10^{17} \text { to } \\
6 \times 10^{17}\end{array}\right. \\
\left\{\begin{array}{l}6 \times 10^{17} \text { to } \\
6 \times 10^{18}\end{array}\right.\end{array}$ \\
\hline 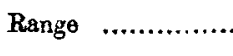 & $10^{2}$ to $10^{21}$ & Range ........... & $10^{12}$ to $10^{20}$ \\
\hline
\end{tabular}

$\dagger$ During the first hour ( 500 to 3000 seconds) after twisting just within the elastic limits,

The limits here defined are somewhat arbitrary. They will be made more definite when a greater number of substances lying on the boundary between the classes have been examined. Information is lacking and particularly desirable in the neighbourhood of Andrews's critical temperature. From Table IX. it does not seem improbable that the critical temperature may be definable by a narrow limit of viscosity, quite apart from the substance operated on. What this limit may be I do not venture to assert, seeing that the viscosity of gases decreases on cooling, whereas that of liquids increases on cooling.

Table IX. gives the positively astounding range of variation of $\eta$, the chief variable of our material environment-a variable which throughout the whole enormous interval in question nowhere fails to appeal to our senses.

Phys. Lab., U.S. Geological Survey, Washington, D.C., U.S.A.

XXXVI. On the Effect of Permanent Elongation on the Cross Section of Hard-drawn Wires. By Professors T. GRAT and C. L. Mess".

T $N$ the course of a series of experiments on the torsional 1 rigidity of metals, forming part of the course of instruction in elasticity in the mechanical laboratory of the Rose Polytechnic Institute, we were somewhat surprised to find a

- Read before the Physical Society of Glasgow University, February 28, 1890. Communicated by Th. Shields, M.A., Secretary. 